\title{
ASSESSMENT OF TEACHING OF CLINICAL SKILLS IN PEDIATRIC DEPARTMENT OF A TERTIARY CARE HOSPITAL
}

\author{
Sabahat Amir ${ }^{1}$, Arshia Munir ${ }^{1}$, Farooq Ahmed², Usman Mahboob³, Imad Ali Shah', Jan Muhammad ${ }^{1}$ \\ ${ }^{1}$ Department of Paediatric, Khyber Teaching Hospital, Peshawar - Pakistan \\ ${ }^{2}$ Department of Medical Education, Khyber Medical College, Peshawar - Pakistan \\ ${ }^{3}$ Department of Medical Education, Khyber Medical University, Peshawar - Pakistan
}

\begin{abstract}
Objective: The aim of this study was to assess the clinical teaching activities in pediatric department of Khyber teaching hospital by finding the prevailing and preferred teaching methods for year 05 MBBS students.

Material and methods: This cross-sectional survey about teaching methods using a validated questionnaire was conducted in the Department of Child Health Khyber Teaching Hospital Peshawar, Pakistan. The survey was conducted including all the year 05 MBBS medical students who completed their pediatric rotation. Descriptive statistical analysis was applied using SPSS 20.

Results: In pediatric department of Khyber Teaching Hospital 200 students of year 05 MBBS completed their 4 weeks of clinical rotation. Bed side teaching was reported to be most frequently used for psychomotor domain i.e. history taking (43.1\%), systemic examinations (47.4\%) and procedural skill (35\%) while 95\% of the students preferred direct observation of their skill performance followed by a debriefing session. Regarding affective domain counselling (66.4\%) and breaking bad news (3.5\%) was taught by didactic method (48.9\%) while students preferred role modelling (21.9\%) along with lectures $(27 \%)$.
\end{abstract}

Conclusion: Considering the responses given by students they preferred to be actively involved during patient encounters and given feed-back during their year 05 MBBS.

Keywords: Teaching methods, Direct observation of procedural skills (DOPS).

This article may be cited as: Amir S, Munir A, Ahmed F, Mahboob U, Shah IA, Muhammad J. Assessment of teaching of clinical skills in Pediatric department of a tertiary care hospital. J Med Sci 2021 January;29(1):38-41

\section{INTRODUCTION}

In the wake of emerging pressures of competency based medical education (CBME), all the institutions are focusing on developing a curriculum to effectively teach knowledge, attitude and skills for safe and effective performance of future physician ${ }^{1,2,3}$. Competencies are descriptors of the skills or a person's performance in the three domains ${ }^{4}$. In Pakistan the road map for undergraduate medical education is a seven star doctor ${ }^{5}$.

The educational goal of clinical teachers is to ensure that students are prepared for effective and safe patient-centered care ${ }^{6}$. Thus the traditional system, relies on expert practitioners to pass their knowledge to students. However, there is an increasing awareness of pedagogies

\section{Correspondence}

Dr. Farooq Ahmed

Department of Medical Education, Khyber Medical

College, Peshawar - Pakistan

Email: drfarooq.ahmed@kmc.edu.pk

Cell: +92-313-379-9901

Date received: $03-11-2020$

Date revised: $\quad 17-01-2021$

Date accepted: 22-02-2021 and clear-cut teaching strategies that scaffold student learning, rather than relying on transmission of knowledge ${ }^{7}$.

Clinical teaching evaluation has been the subject of much discussion among educators, researchers, and administrators in medical schools concerned with the quality of clinical teaching. Students surveys are used evaluate teaching methods and to develop the ones which are more effective ${ }^{8}$. Evaluation through feedback from students regarding the prevailing system of teaching method in pediatric clinical teaching will improve quality of teaching $^{9}$.

\section{MATERIAL AND METHODS}

This cross-sectional study was conducted in the Department of Child Health Khyber Teaching Hospital Peshawar, Pakistan. The study was conducted from April 2019 till November 2019. The study was approved by the Institutional Ethical research board of Khyber Medical College, Peshawar. All the year 05 MBBS students who completed their 4 weeks rotation in pediatric medicine were 
Assessment Of Teaching Of Clinical Skills In Pediatric Department Of A Tertiary Care Hospital.

included. Consent was taken from the students, purpose of the study and any clarification needed about the questionnaire was given to the students at the end of their rotation. The identity of the students was kept anonymous. Non consenting students were excluded

The validated questionnaire consisted of two parts, part 1 was about the prevailing and preferred teaching methods of psychomotor domain (history taking, general physical examination and systemic examination, procedural skills). Four options were given for the prevailing methods used for each skill which were didactic method, bed side teaching, direct observation and any other method used. For the preferred teaching methods 5-point Likert scale was used for the teaching methods of history taking, general physical and systemic examination and procedural skills.

Part 2 of questionnaire was separately used for affective domain. Dichotomous (yes/no) question whether communication skills was taught or not, the topics covered and the preferred teaching methods. The questionnaire was piloted on 44 students year 05 MBBS and their results was not included in the data collection. The data was collected by giving questionnaire to the year 05 MBBS students at the end of their rotation after taking consent and the data collected was analyzed on SPSS version 20.

\section{RESULTS}

A total of 200 students from year 05 MBBS were included in the survey, out of which 137 responsed. Regarding the prevailing teaching methods, the survey showed that bed side teaching was the most frequently used method for teaching history taking of 59 students (43.1\%), general physical and systemic examination 65 students (47.4\%). The procedural skill 48 (35\%) was explained at bed side on patient or by didactic lectures.

Teaching affective domain (non-technical skills) was by didactic lectures $52(38 \%)$ followed by bed side teaching. Direct Observation of the students while history taking, doing examination and procedural skills was least common. Some of the students reported other teaching methods like directed self-learning, teaching by and learning from residents by observing them. The prevailing teaching methods are shown in table 1, 2 and 3.

The survey showed that 69 students (39.4\%) of year 05 MBBS students preferred direct observation of their history taking skill followed by feed-back (figure 1). For procedural skills 61 students (44.5\%) preferred direct observation of procedural skills in real life or practice on a mannequin followed by debriefing (figure 2).

For General physical and systemic examination 95 $(69.3 \%)$ of students preferred direct observation (figure 3). year 05 MBBS medical students reported no formal topic being specified for the affective domain. Counseling and to some extent breaking bad news was taught to them through lectures (table 4,5). The students were either clueless, or preferred role modelling along with didactic lectures for learning affective domain (table 6).

Table 1: Prevailing teaching methods for history taking in pediatric unit

\begin{tabular}{|c|c|c|}
\hline Teaching method & $\begin{array}{c}\text { Number(n) of } \\
\text { positive responses }\end{array}$ & Percentage \\
\hline Didactic method & 21 & 15.3 \\
\hline bedside teaching & 59 & 43.1 \\
\hline $\begin{array}{c}\text { direct observation of } \\
\text { the students }\end{array}$ & 25 & 18.2 \\
\hline others & 32 & 23.4 \\
\hline Total & 137 & 100 \\
\hline
\end{tabular}

Table 2: Prevailing teaching methods for GPE and systemic examination in pediatric unit

\begin{tabular}{|c|c|c|}
\hline Teaching method & $\begin{array}{c}\text { Number(n) of } \\
\text { positive responses }\end{array}$ & Percentage \\
\hline Didactic method & 6 & 4.4 \\
\hline bedside teaching & 65 & 47.4 \\
\hline $\begin{array}{c}\text { direct observation of } \\
\text { the students }\end{array}$ & 34 & 24.8 \\
\hline Others & 31 & 22.6 \\
\hline Total & 137 & 100 \\
\hline
\end{tabular}

Table 3: Prevailing teaching methods for GPE and systemic examination in pediatric unit

\begin{tabular}{|c|c|c|}
\hline Teaching method & $\begin{array}{c}\text { Number(n) of } \\
\text { positive responses }\end{array}$ & percentage \\
\hline Didactic method & 32 & 23.4 \\
\hline bedside teaching & 48 & 35.0 \\
\hline direct observation & 24 & 17.5 \\
\hline Others & 32 & 23.4 \\
\hline Total & 137 & 100.0 \\
\hline
\end{tabular}

History taking

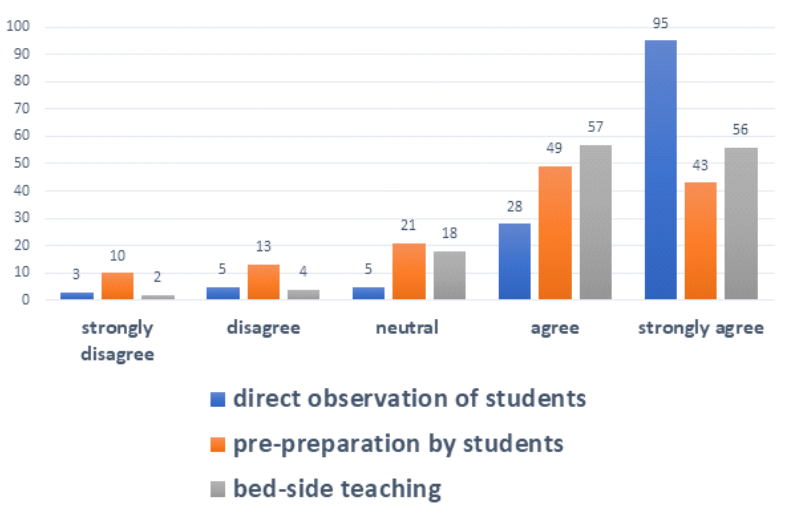

Fig 2: Preferred teaching method by students for history taking. 
Assessment Of Teaching Of Clinical Skills In Pediatric Department Of A Tertiary Care Hospital.

\section{Procedural skills}

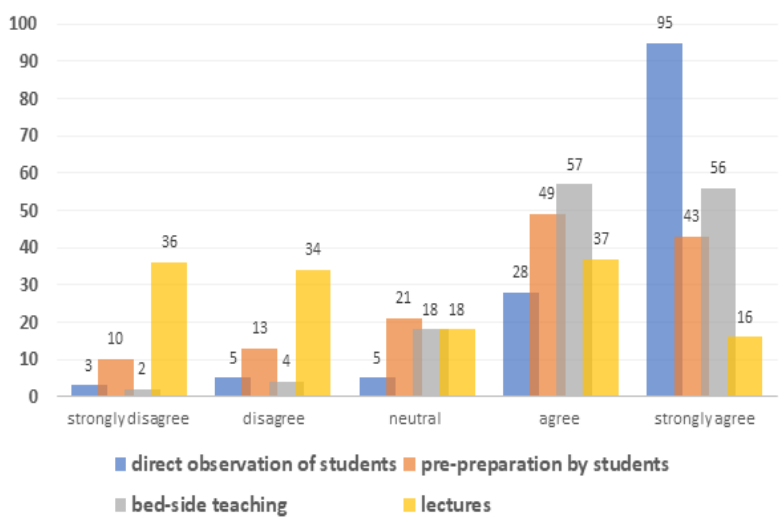

Fig 2: Preferred teaching method by students for procedural skills

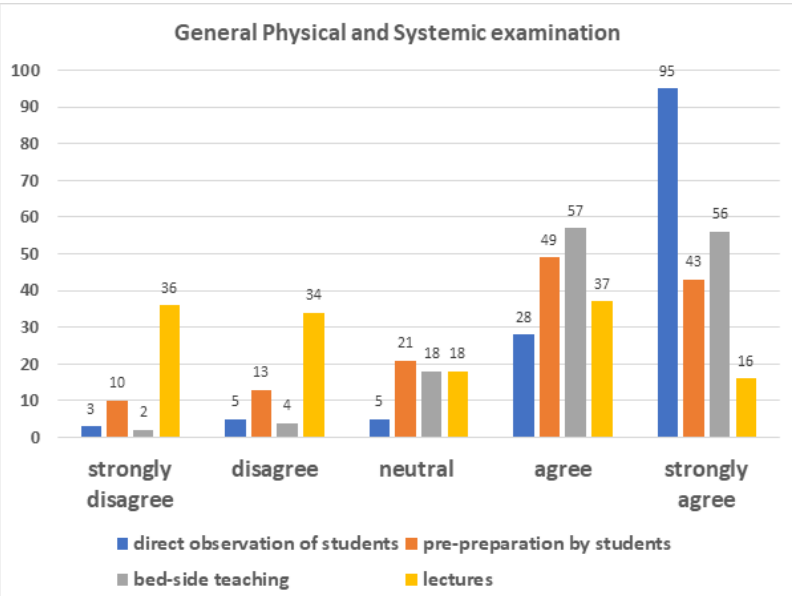

Fig 3: Preferred teaching method by students for teaching General physical and systemic examination

\section{DISCUSSION}

Teaching hospitals provide a key learning environment for the education of medical students ${ }^{7}$. In pediatric units, teaching occurs alongside patient care and service delivery. Effective clinical teaching in pediatric setting is multifactorial, exceeding ordinary teaching and is portrayed by motivating, supporting, actively involving, and communicating with students ${ }^{10}$.

In our study the students reported that the prevailing teaching method was bed side teaching for history taking, physical examination and procedural skills and didactic lectures for communication skills. Remmen $\mathrm{R}$ et al reported that clerkship is usually didactic with passive involvement of the students which affects their performance in residency ${ }^{11}$. While in a systematic review by peter $\mathrm{M}$ and Olle ten Cate, though bed side teaching is passive but is favored by students, teachers and even enjoyed by patients. It improves certain clinical diagnostic skills in medical students and residents ${ }^{12}$. Similarly Z Qureshi et al reported that bed side teaching is experiential learning which facilitates teaching/learning of attitudes and skills related directly to the patient who are present during the learning exercise ${ }^{13}$. The decline in bedside skills is because of de- valuation by medical students and young doctors as well as inadequate faculty development. Proper planning and removal of barriers to bedside teaching will promote this skill ${ }^{14}$. Modeling of clinical encounters has been shown to improve both physical examination and procedural skills, and can be effective for teaching humanism and professional values ${ }^{15}$.

Teaching Procedural skill in a safe environment is an essential component of paediatric clerkship for year 05 MBBS students, but opportunities to teach are limited ${ }^{16}$. The students in our study reported didactic lectures being used in paediatric unit for clinical skills teaching. Remmen $\mathrm{R}$ and et al pointed out in a study that passive roles are delegated rather than active participation to undergraduate medical students in their clinical settings as well ${ }^{11} . \mathrm{J}$ Dehmer et al reported that their students were also given didactic lectures though followed by simulation. Limited exposure to live patients as well as no active participation in procedural skills was also reported in this study ${ }^{16}$. Therefore students are not prepared for their residency and are nervous while performing clinical skills. The students reported that counselling and breaking bad news were the topics taught to them in pediatric unit by didactic lectures. The same is mentioned by Sourya Acharya et al that in the traditional clinical teaching methods, didactic lectures followed by question and answers are used to teach affective domain ${ }^{17}$. The 5 th year students preferred direct observation of clinical skills (history, physical examination and procedures). Gozie Offiah et al also stressed that deliberate practice needs to be encouraged by emphasizing on direct observation and focused feedback to reinforce the skills acquired in the simulated setting ${ }^{18}$. For procedural skill the students preferred direct observation of procedure followed by feed-back and practice on mannequin (simulation). Simulation plays a vital role in teaching procedural skill and is a requirement of integrated teaching and CBME. It will ensure students' competency prior to residency. Simulation can never replace actual patient encounters though it reduces anxiety of newly inducted residents ${ }^{19}$. Thus a combination of simulation and actual patient encounter will provide competent physicians who achieve mile stones of entrustable professional activities ${ }^{16,20}$.

Teaching affective domain was preferred through didactic lectures and role modelling in our study. By observation of role models, and participation in activities, students develop their attitudes, values and professional competencies ${ }^{21}$. Role modeling is a powerful form of learning and an integral part of medical education. Role modeling as an outstanding educational approach has been recommended for enhancing humanism and professionalism in medical education ${ }^{22}$. Teachers and residents must be made aware of this power teaching strategy and its components for a positive effect ${ }^{23}$.

\section{CONCLUSION}

The year 05 MBBS students prefer direct observation of skills followed by debriefing session rather than bedside teaching to achieve competencies in psychomo- 
tor skills and role modeling for affective domain during clerkship in pediatric department. It is a survey relying on students reporting about the prevailing and preferred teaching methods which may be biased.

Strategies and futuristic plans need to be implemented during clerkship of year 05 MBBS so that as residents the students' competencies can be trusted. An interventional study is required to evaluate the change in attitude, skills and behavior of students after teaching them by the preferred teaching methods.

\section{REFERENCES}

1. Snell LS, Frank JR. Competencies, the tea bag model, and the end of time. Med Teach. 2010;32:629-30.

2. Carraccio C, Englander R, Gilhooly J, Mink R, Hofkosh D, Barone MA, et al. Building a Framework of Entrustable Professional Activities, Supported by Competencies and Milestones, to Bridge the Educational Continuum. Acad Med. 2017;92(3):324-30.

3. Caverzagie $\mathrm{K}$, Nousiainen $\mathrm{M}$, Ferguson $\mathrm{P}$, ten Cate $\mathrm{O}$, Ross S, Harris K, et al. Overarching challenges to the implementation of competency-based medical education. Med Teach. 2017 Jun 3;39:588-93.

4. Ten Cate O, Chen HC, Hoff RG, Peters H, Bok H, Van Der Schaaf M. Curriculum development for the workplace using Entrustable Professional Activities (EPAs): AMEE Guide No. 99. Med Teach. 2015;37(11):983-1002.

5. Baig LA, Ali S. Development of the Community-Oriented Medical Education curriculum of Pakistan : A case report on the national initiative on curriculum development Development of the Community-Oriented Medical Education Curriculum of Pakistan : A Case Report on the Natio. Educ Heal Chang Learn Pract. 2006;19(2):223-8.

6. Bannister SL, Raszka WV, Maloney CG. What makes a great clinical teacher in pediatrics? Lessons learned from the literature. Pediatrics. 2010 May 1;125(5):863-5.

7. Van Heerden C, Uahwatanasakul W, Vaughan B, Delany C. Ripple effect of a clinical teaching fellow programme in an Australian paediatric hospital. J Paediatr Child Health. 2020;56(7):1072-6.

8. Pukhta MA, Bhat MY, Singh Z. A questionnaire based study of prevailing teaching methods in pharmacology and its efficacy / evaluation by second professional $M$. B . B . S students. Int J Res Med Sci. 2016;4(6):2218-23.

9. Baradaran Binazir M, Barzegar M, Heidari F. Evaluating clinical teaching in a pediatric hospital in Iran: View points of academic members and medical students. Res Dev Med Educ [Internet]. 2020;9(1):4-4.

10. Potisek NM, Page L, Narayan A, McNeal-Trice K, Steiner MJ. The Association Between Pediatric Faculty Factors and Resident Physician Ratings of Teaching Effectiveness. Glob Pediatr Heal. 2019;6:2333794X1882299.

11. Remmen R, Denekens J, Scherpbier A, Hermann I, Van Der Vleuten C, Van Royen P, et al. An evaluation study of the didactic quality of clerkships. Med Educ. 2000;

12. Peters $\mathrm{M}$, ten Cate $\mathrm{O}$. Bedside teaching in medical education: a literature review. Perspect Med Educ [Internet]. 2014;3(2):76-88.

13. Qureshi Z, Maxwell S. Bedside teaching. Med Teach [Internet]. 2011;33(7):594-5.
14. Ahmed AM. Bedside teaching at the cinderella status: Options for promotion. Saudi Med J. 2010;31 (7):739-46.

15. Stone RT, Tollefson T, Epstein R, Jozefowicz RF, Mink JW. Author response: Education research: Positive effect of scheduled faculty modeling on clerkship student bedside skills exposure and learning. Neurology. 2017;89(19):2023.

16. Dehmer JJ, Amos KD, Farrell TM, Meyer AA, Newton WP, Meyers MO. Competence and confidence with basic procedural skills: The experience and opinions of fourthyear medical students at a single institution. Acad Med. 2013;88(5):682-7.

17. Acharya S, Shukla S, Acharya N, Vagha J, Vagha J. Role play and \#8211; an eff ective tool to teach clinical medicine. J Contemp Med Educ. 2014;2(2):91.

18. Offiah G, Ekpotu LP, Murphy S, Kane D, Gordon A, O'Sullivan $\mathrm{M}$, et al. Evaluation of medical student retention of clinical skills following simulation training. BMC Med Educ. 2019;19(1):1-7.

19. Sell E, Grabowski J, Lobos A-T, Doja A, Moreau KA, McMillan $\mathrm{HJ}$, et al. Lumbar puncture simulation in pediatric residency training: improving procedural competence and decreasing anxiety. BMC Med Educ [Internet]. 2016;16(1):1-7.

20. Pugh D, Cavalcanti RB, Halman S, Ma IWY, Mylopoulos $M$, Shanks D, et al. Using the Entrustable Professional Activities Framework in the Assessment of Procedural Skills. 2017;9(2):209-14.

21. Burgess A, Oates K, Goulston K. Role modelling in medical education: The importance of teaching skills. Clin Teach. 2016;

22. Mirhaghi A, Moonaghi HK, Sharafi S, Zeydi AE. Role modeling: A precious heritage in medical education. Acta Fac Medicae Naissensis. 2015;32(1):31-42.

23. Cruess SR, Cruess RL, Steinert Y. Teaching rounds: Role modelling - Making the most of a powerful teaching strategy. Bmj. 2008;336(7646):718-21.

CONFLICT OF INTEREST: Authors declare no conflict of interest

GRANT SUPPORT AND FINANCIAL DISCLOSURE: NIL

\section{AUTHOR'S CONTRIBUTION}

Following authors have made substantial contributions to the manuscript as under

Amir S: $\quad$ Concept and Design

Munir A: $\quad$ Acquisition and critical review.

Ahmed F: $\quad$ Analysis and interpretation of data.

Mahboob U: Concept and Design.

Shah IA: Data collection.

Muhammad J: Proof reading.

Authors agree to be accountable for all aspects of the work in ensuring that questions related to the accuracy or integrity of any part of the work are appropriately investigated and resolved. 